\title{
Pesquisa de oocistos de Cyclospora sp em fezes de cães da Grande São Paulo, Estado de São Paulo, Brasil
}

\author{
Detection of Cyclospora sp oocysts in the feces of stray dogs \\ in Greater São Paulo (São Paulo State, Brazil) \\ Maria Cristina Casaqui Carollo', Vicente Amato Neto², \\ Lúcia Maria Almeida Braz² e Do Woong Kim²
}

Resumo Amostras de fezes de 140 cães adultos da Grande São Paulo (Estado de São Paulo, Brasil) foram examinadas com a finalidade de procurar oocistos de Cyclospora sp.. Nenhuma infecção por esse coccídeo ficou detectada.

Palavras-chaves: Cyclospora sp. Oocistos. Fezes de cães. Grande São Paulo (Estado de São Paulo, Brasil).

Abstract Fecal samples from 140 adult stray dogs of Greater São Paulo (São Paulo State, Brazil) were examined for Cyclospora sp oocysts. No cases of infection by this coccidium were detected.

Key-words: Cyclospora sp. Oocysts. Dog feces. Greater São Paulo (São Paulo State, Brazil).

Há necessidade de se conhecer melhor aspectos referentes à ciclosporíase no Brasil. Essa protozoose, já detectada em vários tipos de animais, está também relacionada com acometimentos humanos, podendo promover distúrbios. Além disso, agora que imunodepressão, devida a diferentes motivos, é condição comumente existente, a infecção por Cyclospora adquiriu conotação suplementar, pois tornou-se cogitável nesse contexto, do qual a síndrome da imunodeficiência adquirida (AIDS) faz parte. Yai et al ${ }^{4}$ encontraram a Cyclospora em dois cães em São Paulo e que quanto a casos de ciclosporíase humana, Araújo et $\mathrm{al}^{2}$ e Fernandes et $\mathrm{al}^{3}$ relataram os dois diagnósticos efetuados, sendo um em Brasília e o outro em São Paulo.

A revelação da presença de Cyclospora em fezes é relativamente simples, se bem que os métodos utilizáveis estão pouco divulgados, mas devem, de fato, ficarem mais aproveitados, a fim de possibilitarem boas avaliações epidemiológicas, clínicas e terapêuticas.

Por ocasião de averiguação de parasitoses intestinais de cães do biotério da Faculdade de Medicina da Universidade de São Paulo, consideramos oportuno procurar oocistos de Cyclospora sp nas fezes deles.

Examinamos 140 amostras de fezes de cães adultos, aparentemente hígidos, recolhidos em vias públicas da
Grande São Paulo (Estado São Paulo, Brasil) e removidos, semanalmente, para o biotério da Faculdade de Medicina da Universidade de São Paulo. Cada amostra correspondeu a pool de matérias fecais de vários animais. Setenta foram de machos e 70 de fêmeas.

Em tubos com água obtivemos sedimentos para, então, efetuar pesquisa de oocistos de Cyclospora sp pelo método de Kinyoun modificado ${ }^{1}$ e exame parasitológico após centrífugo-flutuação com solução saturada de sacarose, que é técnica comumente usada com essa finalidade. Quanto ao processo de Kinyoun efetuamos esfregaços com alíquotas de $10 \mu \mathrm{l}$ do sedimento e subseqüente fixação por meio do metanol. Caso encontrássemos Cyclospora sp. providenciaríamos esporulação dos oocistos com bicromato de potássio.

Foram identificados os seguintes protozoários e helmintos: Ancylostoma sp 44,3\%; Ancylostoma sp e Giardia sp 2,86\%; Ancylostoma sp e Trichuris vulpis 3,57\%; Ancylostoma sp e Sarcocystis sp 0,71\%; Trichuris vulpis $0,71 \%$; Sarcocystis sp $0,71 \%$. A presença dessas infecções serve para facilitar dedução sobre as condições sanitárias das procedências dos animais.

Não encontramos oocistos nas fezes dos animais que compuseram a casuística.

1. Laboratório de Parasitologia do Instituto de Medicina Tropical de São Paulo. 2. Laboratório de Investigação Médica-Parasitológica do Hospital das Clínicas da Faculdade de Medicina da Universidade de São Paulo, SP, Brasil.

Endereço para correspondência: Prof. Vicente Amato Neto, Av. Dr. Enéas de Carvalho Aguiar, 500, 05403-000 São Paulo, SP, Brasil.

Fax: $5511852-3622$

e-mail:amatonet@usp.br

Recebido para publicação em 16/10/2000. 


\section{REFERÊNCIAS BIBLIOGRÁFICAS}

1. Amato Neto V, Braz MLA, Pietro AOD, Módolo JR. Pesquisa de oocistos de Cryptosporidium sp. em fezes: comparação entre os métodos de Kinyoun modificado e de Heine. Revista da Sociedade Brasileira de Medicina Tropical 29: 575-578,1996.

2. Araújo ALT, Teramussi LA, Mangini ACS, Freitas EG, Hakme NA, Lins NS. Descrição de um caso de cyclosporose em paciente portador de SIDA/AIDS, Brasília - DF, Brasil. Revista de Patologia Tropical 23 (supl II): 244, 1994.
3. Fernandes AODP, Carollo MCC, Braz MLA, Amato Neto V, Villela $\mathrm{MSH}$. Human cyclosporiasis diagnosis: report of a case in São Paulo, SP, Brazil. Revista do Instituto de Medicina Tropical de São Paulo 40: 391-394, 1998.

4. Yai LEO, Baub AR, Hirschfeld MPM, Oliveira ML, Damaceno JT. The first two cases of Cyclospora in dogs, São Paulo, Brazil. Revista do Instituto de Medicina Tropical de São Paulo 39: 177179, 1997. 